\title{
An argument for ezafe constructions and construct state in Zulu
}

\author{
Taylor Jones*
}

\begin{abstract}
Zulu (Niger-Congo, South Africa) exhibits a complicated interplay between morphological and phonological processes that, combined with an inherited, traditionalist approach to syntactic categories in the Nguni languages, obscures an overt phoneme that is argued to be common to all complex DPs. Here it is claimed that the traditional categories of adjective, relative, compound noun, possessive, and demonstrative can all be unified under a DP approach that takes this overt phoneme to be a functional marker that is analogous to those appearing in Persian ezafe constructions and construct state constructions in Afro-Asiatic languages. This approach reduces a variety of seemingly different Zulu-specific phenomena to a single, cross-linguistically established phenomenon.
\end{abstract}

Keywords. Zulu; Persian; construct state; ezafe; determiner phrase

1. Introduction. This paper argues that a wide range of DP phenomena in Zulu can be conceptually reduced to the same phenomenon; one which is not Nguni or even Bantu specific (cf. Halpert 2012 on Zulu, and Baker 2003, Baker 2008, Diercks 2012 after discussion in Halpert 2012). It is shown that complex DPs in Zulu all exhibit the same "linking" vowel (also called the associative marker, see Pietraszko To appear for discussion ${ }^{1}$ ). While Zulu noun class augments (or pre-prefixes) are generally taken to be determiners due to facts about their patterning in certain environments (e.g., their phonological absence in some kinds of negation, their absence in vocatives, etc., see de Dreu 2008, Halpert 2012 inter alia), here I remain agnostic as to the nature of the class augment, and instead pursue a different avenue of investigation, which takes the "linking" /a/ to be a functional head, potentially an overt realization of $\mathrm{D}$. This reduces the required architecture to analyze Zulu nominals, and brings a wide range of phenomena under the same conceptual umbrella. It eliminates the need for an extra projection in the nominal domain to explain the linking vowel (LnkP by some accounts), and eliminates the need for a DP shell analysis (Pietraszko To appear) for relatives.

The core of the proposal is that the phonological evidence suggests that all complex noun phrases in Zulu exhibit an overt /a/, possibly more than one, which links each element of the noun phrase and triggers lowering of high vowels. I propose two new ways of interpreting these data, a weak claim and a strong claim. The weak claim is that these data pattern with Persian ezafe constructions, and that the most parsimonious explanation of the data will be that the Zulu structure is analogous to the Persian structure, whatever the correct analysis of Persian ezafe turns out to be (it is not settled in the literature on Persian). The strong claim is that this /a/ is an overt realization of $\mathrm{D}$. An even stronger claim that falls out from this is that the evidence suggests some Zulu deverbal noun phrases may exhibit the same structure as the Semitic construct state. In section 2, I discuss Persian ezafe constructions and the construct state. In section 3, I discuss Zulu morphophonology. In section 4, I present the evidence that Zulu

\footnotetext{
* Special thanks to Audrey Mbeje, Dave Embick, and Julie Legate for their guidance, and to David Wilson Luke Adamson, and Kajsa Djarv for helpful discussion. Author: Taylor Jones, University of Pennsylvania

${ }^{1}$ At the 2018 Annual Meeting of the Linguistic Society of America I was made aware of Peitraszko's forthcoming work in which the morphophonological facts are decomposed in the same way as presented here (but analyzed differently).
} 
"linking" /a/ occurs in more environments than it is usually taken to (e.g., not just adjectives and relatives), and propose a different way of looking at the structure of the noun phrase in Zulu. In section 5, I explain why previous discussions of the Zulu DP do not necessarily adequately address these data, and new questions this analysis raises. Section 6 concludes.

2. Persian ezafe and Semitic construct state. Ezafe is a term from Persian, borrowed from Arabic idaafa, referring to a specific morphosyntactic pattern in Persian DPs. While the name is borrowed from the Arabic term for what, in the literature on Semitic languages, is referred to as the construct state, whether it should be classified as such in the modern generative tradition is not clear, as, for example, Adger (2003, following Ritter 1988) argues that construct state should refer only to constructions for which the theme in a DP with a VP equivalent occurs before the agent (example 1). ${ }^{2}$ The term ezafe is used here to avoid prematurely making a stronger claim about Zulu than may be warranted, although see section 4.3 for evidence for construct state.
a. harisat ha- oyev 'et ha- 'ir destruction the enemy OM the city 'the enemy's destruction of the city'
b. tipul ha- šiltonot ba- ba'aya treatment the authorities in problem 'the authorities' treatment of the problem'

In Persian, modified nouns occur with a linking morpheme, realized as the suffix $-(y) e$. It occurs with adjectives, compound nouns, genitives, possessives, and PPs (example 2). It is glossed below as EZ.

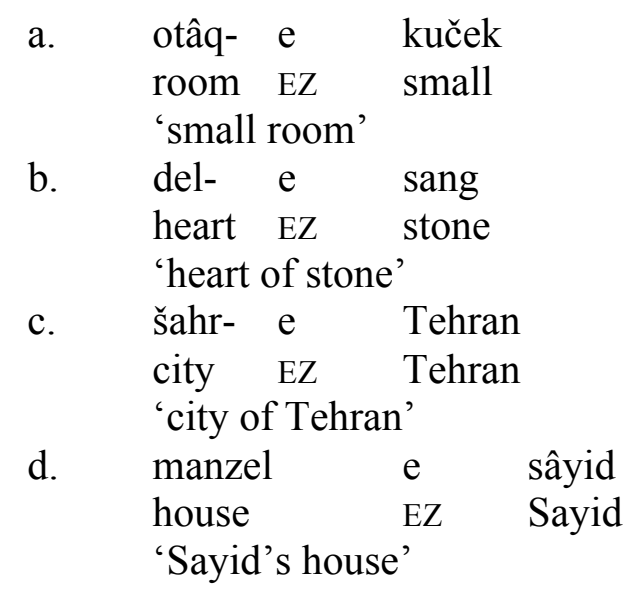

It links all elements of a complex noun phrase, and can occur, in principle, unlimited times (example 3).

The key observation for the following is that Persian DPs all exhibit a linking - (y)e, and that this morpheme links all items in a single DP which may then play some thematic role in the sentence, and that other marking on the DP, for instance indefiniteness or direct object marking, occurs outside of the whole phrase (example 4).

\footnotetext{
${ }^{2}$ Adger (2003), for instance, takes state to refer to only instances in which "the $\mathrm{N}+\mathrm{n}$ complex ... raise[s] to D and the agent ... stay[s] in situ."
} 


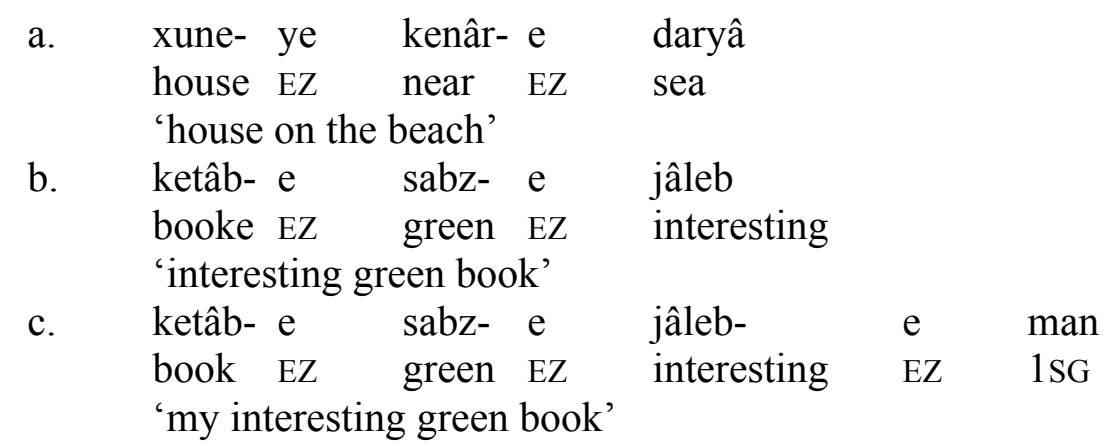

\begin{tabular}{|c|c|c|c|c|c|c|c|c|c|}
\hline $\begin{array}{l}\text { ketâb- } \\
\text { book }\end{array}$ & $\begin{array}{l}\mathrm{e} \\
\mathrm{EZ}\end{array}$ & $\begin{array}{l}\text { sabz- } \\
\text { green }\end{array}$ & $\begin{array}{l}\mathrm{e} \\
\mathrm{EZ}\end{array}$ & $\begin{array}{l}\text { jâleb- } \\
\text { interesting }\end{array}$ & $\begin{array}{l}\mathrm{e} \\
\mathrm{EZ}\end{array}$ & $\begin{array}{l}\operatorname{man}] \\
1 \mathrm{SG}\end{array}$ & $\begin{array}{l}-\mathrm{O}] \\
\mathrm{OBJ}\end{array}$ & $\begin{array}{l}\text { na- } \\
\text { NEG }\end{array}$ & $\begin{array}{l}\text { didam } \\
\text { I.saw }\end{array}$ \\
\hline
\end{tabular}

3. Zulu morphophonology. Zulu has a five vowel system with /i/, /e/, /a/, /o/, and /u/. The mid vowels have lax allophones when preceding the low vowel. In Zulu, vowels do not generally surface in hiatus. Rather, one of four phonological processes blocks hiatus: consonant insertion, glide formation, deletion, or coalescence. The low vowel /a/ triggers lowering of the high vowels /i/ and /u/ when in hiatus, and two low vowels coalesce:

- $\mathrm{ai} \rightarrow \mathrm{e}$

- $a u \rightarrow 0$

- $a \mathrm{a} \rightarrow \mathrm{a}$

$$
\begin{array}{llllll}
\text { ngi- } & \text {-na- } & -\mathrm{i}- & - \text { nja } & \rightarrow & \text { 'nginenja' } \\
\text { 1SG.SUBJ } & \text { with } & 9 & \operatorname{dog} & & \\
\text { 'I have a dog' }
\end{array}
$$

Zulu has fourteen noun classes, none of which exhibit a mid vowel twelve of which begin with high vowels, making the phonological evidence of an adjacent /a/ overt in all but two classes. The class markers are summarized in Table 1 (note, $\mathrm{N}$ refers to a nasal that agrees in place with the following segment, e.g., inja 'dog' and impondo 'handlebar'. Segments in parentheses are generally taken to be part of the prefix because they are the subject agreement marker, but do not surface on the noun).

\begin{tabular}{llll} 
Singular & Plural & Abstract & Infinitive/deverbal \\
\hline umu & aba & ubu & uku \\
umu & imi & & \\
i(li) & ama & & \\
isi & izi & & \\
iN & iziN & & \\
u(lu) & iziN & & \\
\hline
\end{tabular}

Table 1: Zulu noun class markers

All nouns in Zulu are licensed by a class marker and do not appear without one. Complex DPs exhibit a sophisticated system of agreement, wherein noun classes appear to "stack". Only adjectives, of which there are 15, retain nasals in their class marker in complex DPs. While Zulu has a wide range of what would be considered adjectives in other languages, they all can behave as verb stems. Because of the retention of nasals in attributive adjectives, and the productive way 
in which other seemingly inherently verbal stems can modify nouns, Zulu has historically been analyzed as having a small closed class of adjectives, a productive class of relatives, and a number of other grammatical categories occurring in nominal phrases, both cross-linguistically common (possessives, compound nouns, demonstratives) and Bantu or Zulu specific (quantitative concords, "one" concords, etc.).

As noted above, only adjectives retain their noun class marker nasals in attributive use. So-called relatives delete the nasal, putting vowels in hiatus. If DPs have an overt /a/, this will be present in the phonology, but will interact with these facts. In 3.1 I put forth a minimal proposal for a possible parsimonious interpretation of the structure of Zulu DPs. The analysis requires phonological agreement, and, following Chomsky (1995) assumes agreement requires ccommand.

4. A proposed structure for Zulu DPs. Simple nouns in Zulu must have a licensing class marker. The same stem may appear with different class markers, and have different meanings (example 6).

$\begin{array}{lll}\text { a. } & \text { umu- ntu } \\ & 1 \text { person } \\ & \text { 'a person' } \\ \text { b. } & \text { aba- ntu } \\ & 2 \text { person } \\ & \text { 'people' } \\ \text { c. } & \text { ubu- ntu } \\ & 14 \text { person } \\ & \text { 'humanity' }\end{array}$

Once this noun is licensed, it can enter into more complicated relationships. I argue the class marker on the noun licenses adjectives through agreement, and that the appropriate surface structure to analyze, from the phonological evidence, is:

$$
\mathrm{CL}_{1}-\mathrm{N} / \mathrm{a} /-\mathrm{CL}_{1}-\mathrm{ADJ}
$$

Here, CL stands for "class," $\mathrm{N}$ for "noun", ADJ for "adjective" and I remain agnostic here about the category of /a/. The structure for relatives, in their simplest form, is the same, however nasals do not occur in the agreeing class marker (example 8):

$$
\mathrm{CL}_{1}-\mathrm{N} / \mathrm{a} /-\mathrm{CL}_{1} \text {-REL } \quad \text { (*NAS in agreeing class marker) }
$$

This correctly captures the relevant facts for adjectives and (simple) relatives (example 9).

$\begin{array}{lllll}\text { a. umu- ntu a- } & \text { umu- de } \rightarrow & \text { umuntu omude } \\ 1 \text { person } / \mathrm{a} / & 1 & \text { tall } & & \\ \text { 'a tall person' } & & & & \\ \text { b. umu- ntu a- } & \text { umu- qotho } \rightarrow & \text { umuntu oqotho } \\ & 1 \text { person } / \mathrm{a} / & 1 & \text { honest } & \\ \text { 'an honest man' } & & & \end{array}$

In $9 \mathrm{a}$, the /a/ and umu- class marker coalesce: $a$-umu-de becomes omude. In $9 \mathrm{~b}$, the nasal is deleted so $a$-umu-qotho becomes $a$-uu-qotho, the identical vowels in hiatus coalesce yielding $a$ $u$-qotho, and then the /a/ and class vowel coalesce, resulting in oqotho. 
It should be noted that the /a/ does not occur in predicative use. That is, it does not appear outside of a DP.
a. [DP umu- ntu $]$ mu- de $\rightarrow \quad$ umuntu mude 1 person 1 tall 'the person is tall'
b. [DP Umu- ntu ] u- qotho $\rightarrow$ umuntu uqotho 1 person 1 SUBJ honest 'the man is honest'
c. [DP in- cwadi yi- ] ng- ubu- so $\rightarrow$ incwadi yingubuso 9 book 9.SUBJ COP 14 face ? 'the book is a face'

Compound behave similarly, however each noun is licensed by a class marker (recall that the choice of class marker carried semantic information), and the modifying noun further agrees with the head noun, as in example 11:

$$
\mathrm{CL}_{1}-\mathrm{N}_{1} \mathrm{CL}_{1}-/ \mathrm{a} /-\mathrm{CL}_{2}-\mathrm{N}_{2}
$$

An example of such a structure is the name for Facebook in Zulu:

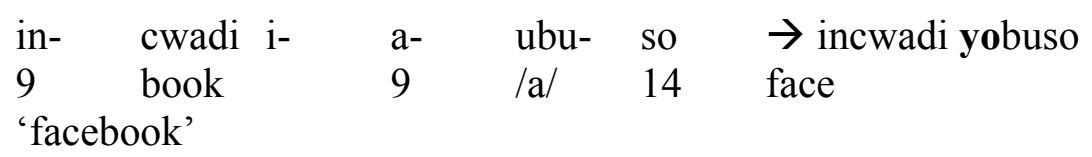

Here, the underlying structure is $i-a-u b u-s o$, but the /a/ and initial vowel of the class marker coalesce ( $i$-obuso), and the class 9 agreement marker, agreeing with incwadi 'book', becomes a glide, yielding incwadi yobuso. I argue that possessives follow the same pattern, schematized in 13:

$$
\mathrm{CL}_{1}-\mathrm{N}_{1} \mathrm{CL}_{1} \text {-/a/-PRN } \quad \text { (*NAS in agreeing class marker) }
$$

Here, PRN stands for "pronoun”. Example 14 shows sample sentences with possessives.
a. in- cwadi i- a- mi $\rightarrow$ incwadi yami
9 book $\quad 9 \quad / \mathrm{a} / \quad 1 \mathrm{SG}$
'my book' 14 medicine/tree $14 \quad$ /a/ $2 \mathrm{SG}$
'her medicine'
b. umu- thi u- a- khe $\rightarrow$ umuthi wakhe

Similarly, demonstratives can be brought under the same umbrella. Zulu has proximate, medial, and distal demonstratives. I argue that the demonstrative stem is simply $l$-, which combines with /a/ and then medial or distal markers, as in 15, with examples in 16:

$$
\begin{aligned}
& \left(\mathrm{CL}_{1}-\mathrm{N}_{1}\right) \mathrm{DEM}-/ \mathrm{A} /-\mathrm{CL}_{1}(\mathrm{MED} / \mathrm{DIST})\left(\mathrm{CL}_{1}-\mathrm{N}_{1}\right) \\
& \text { a. } \quad 1-\quad \text { a- } \quad \text { u- } \quad(\mathrm{u}) \text { mu- ntu } \rightarrow \text { lo muntu } \\
& \text { dem /a/ } 1 \quad 1 \text { person } \\
& \text { 'this person' }
\end{aligned}
$$


Note that in demonstrative structures, the first vowel of the class marker is not always pronounced. It is obligatory if the noun preceeds the demonstrative, as in umuntu lo 'this person', but is optional when the noun follows: lo muntu 'this person'.

4.1 SYNTAX OR PHONOLOGY? The current analysis departs from previous analyses in a number of ways, but all arise from a difference in where variation is assumed to be syntactic versus phonological. Because Zulu is an agglutinative language, any researcher must make decisions about how to divide a word or phrase to analyze. The key observations in support of this analysis are first, that while it has not historically been analyzed this way, there is a strong phonological argument to be made that /a/ appears in all complex nominals; second, that this /a/ does not appear across phrase boundaries; third, that other known morphophonological processes can be adduced to eliminate the need for, say, separate subject relative markers in Zulu; and finally, this /a/ can evidently appear multiple times in complex noun phrases exactly where one would expect to find a functional head.

The first argument was made in the previous section. A simple schematization of the proposed structure of a subset of Zulu DPs is presented in Table 2.

\begin{tabular}{ll} 
Type of DP & Proposed Structure \\
\hline adjective & $\mathrm{CL}_{1}-\mathrm{N} / \mathrm{a} /-\mathrm{CL}_{1}-\mathrm{ADJ}$ \\
relative & $\mathrm{CL}_{1}-\mathrm{N} / \mathrm{a} /-\mathrm{CL}_{1}-\mathrm{REL}$ \\
& $\left({ }^{*} \mathrm{NAS}\right.$ in agreeing class marker $)$ \\
compound noun & $\mathrm{CL}_{1}-\mathrm{N}_{1} \mathrm{CL}_{1} / \mathrm{a} /-\mathrm{CL}_{2}-\mathrm{N}_{2}$ \\
possessive & $\mathrm{CL}_{1}-\mathrm{N}_{1} \mathrm{CL}_{1} / \mathrm{a} /-\mathrm{PRN}$ \\
& $\left({ }^{N} \mathrm{NAS}_{1}\right.$ in agreeing class marker $)$ \\
& $\left(\mathrm{CL}_{1}-\mathrm{N}_{1}\right)$ DEM-/A/-CL $(\mathrm{MED} / \mathrm{DIST})\left(\mathrm{CL}_{1}-\mathrm{N}_{1}\right)$ \\
\hline
\end{tabular}

Table 2: Schematization of the proposed DP structure

The second observation is that the /a/ does not occur across phrase boundaries, so, as discussed above, predicative adjectives lack the /a/ (as well as the class augment). In other analyses, the augment has been taken to be a determiner, because of its absence in negative and some nonveridical environments, with Halpert (2012) and de Dreu (2008) taking a reported meaning contrast between negative sentences with and without the augment (on the direct object) as a starting point:

\section{(17) Reported meaning contrast with augment}

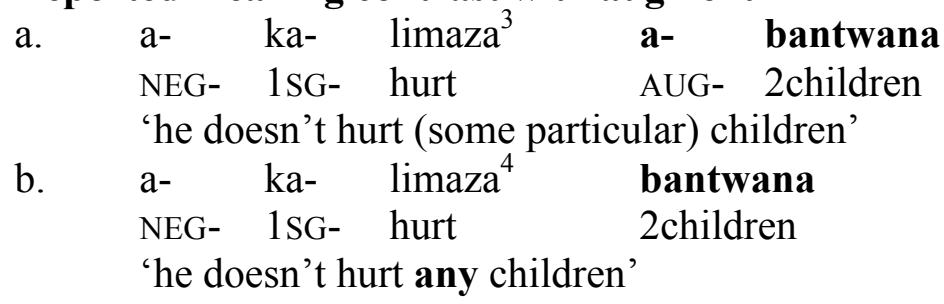

(de Dreu 2008)

However, this analysis is flawed for a number of reasons (ignoring the error in negation marking on the verb). First, the meaning in 17 a is better glossed as contrastive in the sense that 'he

\footnotetext{
${ }^{3}$ This should be akalimazi (Mbeje, p.c.; however, cf. Nyembezi 1957, or Mbeje 2005), however the error reproduced here is in the original examples.

${ }^{4}$ Same as above, this should be akalimazi.
} 
doesn't hurt children' (but perhaps he hurts animals) (Mbeje, p.c.). Second, it leaves out the utterance with a neutral reading, which includes the noun augment and an object marker on the verb (Mbeje, p.c. example 18a), and ignores fronting of the object, which also includes the noun augment (example 18b).

$$
\begin{array}{llllll}
\text { a. a- } & \text { ka- } & \text { ba- } & \text { limazi } & \text { a- } & \text { bantwana } \\
\text { NEG } & \text { 1.SG } & \text { 2.OBJ hurt.NEG AUG } & \text { 2children } \\
\text { 'he doesn't hurt children' } & & \\
\text { b. } & \text { a- bantwana, a- } & \text { ka- } & \text { limazi } \\
\text { AUG } & \text { 2children } & \text { NEG } & \text { 1SG } & \text { hurt.NEG } \\
\text { 'Children, he doesn't hurt' } & &
\end{array}
$$

Third, the deletion of the augment does not happen with all kinds of negation, weakening the argument for augmentless NPI nominals. For instance, hhayi 'not' does not trigger this deletion (example 19).

\begin{tabular}{|c|c|c|c|}
\hline $\begin{array}{l}\text { akekho } \\
\text { there.is.no }\end{array}$ & $\begin{array}{ll}\text { muntu } & \text { o- } \\
\text { man } & \text { REL }\end{array}$ & $\begin{array}{l}\text { limaza a } \\
\text { hurts AUG }\end{array}$ & $\begin{array}{l}\text { bantwana } \\
\text { 2.children }\end{array}$ \\
\hline
\end{tabular}

$$
\begin{array}{llll}
\text { in- doda, hhayi um- fana } \\
9 \text { man NEG } 1 & \text { boy } \\
\text { 'a man, not a boy' } & &
\end{array}
$$

Fourth, this deletion only occurs with objects, not subjects. That is, it is not possible to say something like 'no man hurts children', rather, the structure must be that in example 20, 'there is no man who hurts children' (or, 'there is no child-hurting man'):

Here, I gloss $o$ - as a relative marker, however I will argue below that it is morphologically more complex, and can be reduced to the same general phenomenon discussed above.

Crucially for this analysis, the augment does not appear across phrase boundaries with predicative adjectives (Table 3). Previous analyses taking the deletion of the augment in verbal negation to be indicative of NPI behavior implicitly raise, and leave unanswered, the question of why the augment disappears in predicative adjectives. ${ }^{5}$

Generally, the agreement marking on adjectives and relatives is treated as a separate concord, and so there are (verbal) subject concords, adjectival concords (both predicate and attributive), relative concords, etc. A comparison of relatives and verbal use is presented in Table 4.

However, there is no need for all of this structure if we treat adjectival and relative concords as a class agreement marker licensed by the head noun, and preceded by /a/ in the same DP (but not when across phrase boundaries). In fact, all of the so-called relative subject concords are amenable to an analysis in which they are the (full) class marker of the noun they modify, with nasals deleted, preceded by the functional morpheme /a/, which triggers vowel coalescence and lowering (Table 5).

\footnotetext{
${ }^{5}$ Or, for that matter, when demonstratives precede the noun, but not when demonstratives follow the noun.
} 


\begin{tabular}{|c|c|c|c|}
\hline Attributive & gloss & predicative & gloss \\
\hline Umfana omkhulu & big boy & Umfana mkhulu & $\begin{array}{l}\text { The boy is } \\
\text { big. }\end{array}$ \\
\hline Umuthi omuhle & good medicine & umuthi muhle & $\begin{array}{l}\text { the medicine } \\
\text { is good }\end{array}$ \\
\hline Ihhashi elincane & small horse & ihhashi lincane & $\begin{array}{l}\text { the horse is } \\
\text { small }\end{array}$ \\
\hline Isitsha esihle & good dish & isitsha sihle & $\begin{array}{l}\text { the dish is } \\
\text { good }\end{array}$ \\
\hline Inja enkulu & big dog & inja inkulu & the dog is big \\
\hline Izinja ezinkulu & big dogs & izinja zinkulu & $\begin{array}{l}\text { the dogs are } \\
\text { big }\end{array}$ \\
\hline U(lu)thi olude & long stick & uthi lude & $\begin{array}{l}\text { the stick is } \\
\text { long }\end{array}$ \\
\hline
\end{tabular}

Table 3: Attributive and Predicative Adjectives

\begin{tabular}{|c|c|c|c|}
\hline Attributive & gloss & Predicative & gloss \\
\hline Umfana oqotho & an honest boy & Umfana uqotho & $\begin{array}{l}\text { the boy is } \\
\text { honest }\end{array}$ \\
\hline Abafana abaqotho & honest boys & Abafana baqotho & $\begin{array}{l}\text { the boys are } \\
\text { honest }\end{array}$ \\
\hline Umuthi obomvu & red tree & Umutu ubomvu & the tree is red \\
\hline Imithi ebomvu & red trees & Imiti ibomvu & the trees are rec \\
\hline I(li)qiniso elinqunu & the naked truth & I(li)qiniso linqunu & $\begin{array}{l}\text { the truth is } \\
\text { naked }\end{array}$ \\
\hline Amatshe ambalwa & a few stones & Amatshe ambalwa & $\begin{array}{l}\text { the stones are } \\
\text { many }\end{array}$ \\
\hline isihlalo esibomvu & red chair & Isihlalo sibomvu & the chair is red \\
\hline Izihlalo ezibomvu & red chairs & Izihlalo zibomvu & $\begin{array}{l}\text { the chairs are } \\
\text { red }\end{array}$ \\
\hline Indlu emnyama & black house & Indlu imnyama & $\begin{array}{l}\text { the house is } \\
\text { black }\end{array}$ \\
\hline Izindlu ezimyama & black houses & Izindlu zimyama & $\begin{array}{l}\text { the houses are } \\
\text { black }\end{array}$ \\
\hline $\begin{array}{l}\text { u(lu)donga } \\
\text { olumhlophe }\end{array}$ & white wall & $\begin{array}{l}\text { u(lu)donga } \\
\text { lumhlophe }\end{array}$ & $\begin{array}{l}\text { the wall is } \\
\text { white }\end{array}$ \\
\hline izindonga ezimhlophe & white walls & $\begin{array}{l}\text { izindonga } \\
\text { zimhlophe }\end{array}$ & $\begin{array}{l}\text { the walls are } \\
\text { white }\end{array}$ \\
\hline ubuhlalu obuluhlaza & green/blue beads & Ubuhlalu buluhlaza & $\begin{array}{l}\text { the beads are } \\
\text { blue/green }\end{array}$ \\
\hline $\begin{array}{l}\text { Ukukhanya } \\
\text { okubomvu }\end{array}$ & red light & $\begin{array}{l}\text { ukukhanya } \\
\text { kubomvu }\end{array}$ & the light is red \\
\hline
\end{tabular}

Table 4: Attributive and 'Predicative' Relatives 


\begin{tabular}{llll} 
Class & Class marker & Relative concord & Subject concord \\
\hline 1 & umu- & o- & u- \\
2 & aba- & aba- & ba- \\
3 & umu- & o- & u- \\
4 & imi- & e- & yi- \\
5 & i(li)- & eli- & li- \\
6 & ama- & a- & a- \\
7 & isi- & esi- & si- \\
8 & izi- & ezi- & zi- \\
9 & i(N)- & e- & yi- \\
10 & izi(N)- & ezi- & zi- \\
11 & ulu- & olu- & lu- \\
12 & izi(N)- & ezi- & zi- \\
13 & ubu- & obu- & bu- \\
14 & uku- & oku- & ku- \\
\hline
\end{tabular}

Table 5: Class markers, relative markers, and subject concords

Rather than treating the relative concord as a separate subject concord used in relative clauses, it may be easier to think of the relative concord as the combination of a noun class marker agreeing with the licensing head noun within a DP structure where they are linked by an overt functional morpheme /a/, while subject to the *NAS constraint. Such an analysis is justified by the phonology, and creates a simpler, more parsimonious account of relative marking - one which is consistent with other languages (e.g., Sumerian; A. Bacovcin \& D. Wilson, p.c.). An example of how this might work with a class $1(u m u-)$ noun is presented in example $9 \mathrm{~b}$, reproduced in example 21.

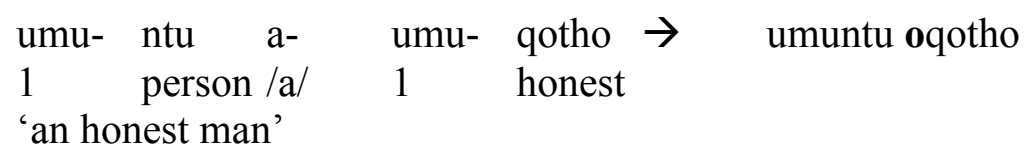

Using an ordered rule approach to the phonology assuming cyclic application (in a Lexical Phonology framework, following Kiparsky 1982, Kaisse 1985, Mohanan 1986, inter alia), ${ }^{6}$ we could say that $a$-umu-qotho is first subject to the deletion of the nasal segment, then the two vowels in the class marker coalesce. This puts the class marker, now just $u$, in hiatus with the functional /a/, which coalesce in the next phonological cycle.

Finally, exactly as with Persian ezafe constructions, multiple items in a complex DP all are linked by functional /a/, interacting with class marker agreement (licensed through ccommand). For example, in 22 the first two sentences have adjectives and possessives, and the third has two modifiers on the noun. In example 22c, the phrase umuntu wesifazane owaliwe is a set phrase meaning 'a divorced woman' and it would be a mistake to analyze it as a noun modified by multiple relative clauses (that is, as 'a person who is a woman who is fallen').

To make the above concrete, a simple derivation for incwadi yobuso 'facebook' provided below. This broad-strokes derivation is consistent with both Distributed Morphology (following Embick 2015) and a number of approaches current in the minimalist framework, following

\footnotetext{
${ }^{6}$ Whether one uses ordered rules or Optimality Theory does not significantly affect the analysis.
} 
Adger (2003) on the internal structure of the DP, but consistent with others. First, nominal stems are licensed by class markers (example 23).

a. umlenze wakhe obuhlungu

$\begin{array}{llllll}\text { um- lenze } & \mathbf{u}- & \text { a- } & \text { khe } & \text { a- } & \text { ubuhlungu } \\ 1 & \text { leg } 1 & \text { /a/ } & \text { his } & \text { /a/ } & \text { 13painful } \\ \text { 'his painful leg' }\end{array}$

(Nyembezi 1957)

b. umntwana wakhe omhlophe qwa

um- ntwanau- a- $\quad$ khe a- $\quad$ u- mhlope qwa

'his very white child' $\quad$ (Nyembezi 1957)

c. umuntu wesifazane owaliwe

$\begin{array}{lllllll}\text { umu- } & \text { ntu } \quad \text { u- } & \text { a- } & \text { isi- } & \text { fazane a- } & \text { u- } & \text { aliwe } \\ 1 & \text { person } 1 & \text { /a/ } & 7 & \text { woman/a/ } & 1 & \text { fallen } \\ \text { 'a divorced woman' } & & & & & \end{array}$

(23)

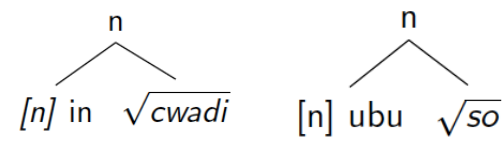

Both are merged in NP (example 24).

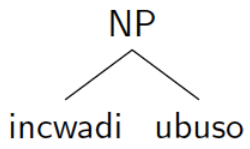

Ubuso 'face' raises to $\mathrm{nP}$ (example 25).

(25)

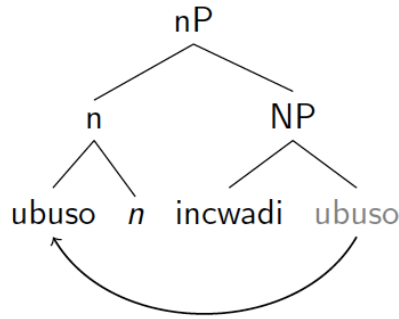

Next, the linking /a/, treated as the head of DP, here, is added to the derivation (example 26). Other theoretical approaches are possible, but this is a starting point for future analyses. Note that this is only possible if we assume the augment isn' $t$ the head of DP. Finally, incwadi 'book' raises to the specifier of DP (example 27).

There are a number of ways of operationalizing this approach, and I have intentionally omitted a more nuanced discussion of agreement, but it should be noted that whatever is modifying the head noun will exhibit agreement with the class marker for the head noun, and if it is another noun, will have both its own licensing class marker and agreement with the head noun. 


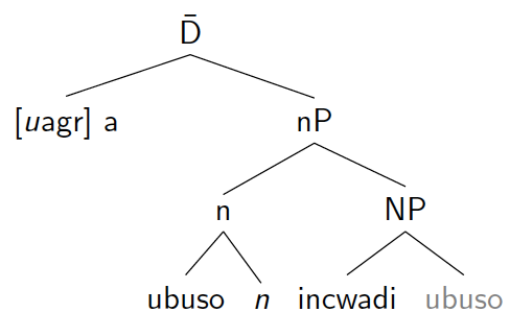

(27)

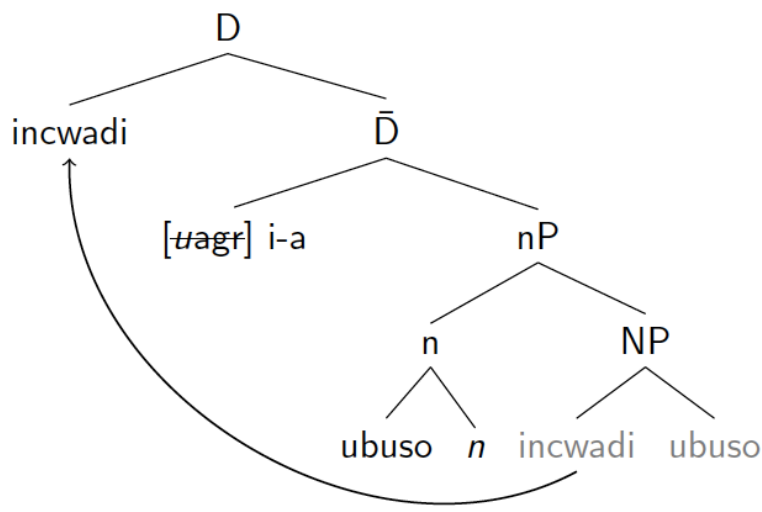

4.2 RELATIVE CLAUSES AND MODIFICATION OF NOUNS. While the literature on Zulu assumes relative clauses marked with relative subject concords, this is in part based on assumptions inherited from earlier analyses of the language that predate modern linguistics. The above analysis treats adjectives as basically a subset of things that modify nouns, and which constitute a closed class that retain nasals in class agreement markers. For many relatives, it makes sense to treat them the same as adjectives in other languages (for instance, basic color terms belong to the relative class, and cannot be used as verbs). Many of the adjectives in Zulu are precisely the same kinds of adjectives that behave peculiarly cross linguistically, for instance, preceding the verb in French (the so-called beauty, age, goodness, and size adjectives). For this reason, it may be profitable to think of all relatives in Zulu not (necessarily) as relative clauses, but as modification of the noun within DP. That is, just as many English speakers allow for modification of the noun with sentences like those in example 28, we might think of all relatives in Zulu as basically behaving like adjectival modification:

(28) a. I don't have a specific [it has to look like this] idea

b. It was almost [knock you over] wind

c. It's a vacation house, not a [live there] house

d. It's writing desk, not a [leave a pile of books and papers on it] desk

e. I need an overnight flight, not a [during the day] flight

f. That's the [be careful because if you sit on it wrong the chair might break] chair

g. I gave her a [don't-you-dare!] look.

(Bruening 2017).

For instance, we can think of example 20 above as 'there is no child-hurting man' or 'there is no he-hurts-kids guy'. Similarly, we can interpret umuntu oqotho owunakekelayo umndeni wakhe as 
'a person who is honest and who takes care of his family', or, following the morphophonological marking, as 'an honest, takes-care-of-his-family guy' This is shown in example 29 (with bold and italics used to group agreement markers).

$\begin{array}{llllllll}\text { umu- } & \text { ntu } \quad \text { o- } & \text { qotho o- } & w u \text { - } & \text { nakekela- } & \text { yo } & u m- & \text { ndeni } u \text { - } \\ 1 & \text { person REL } & \text { honest REL } & \text { 1OBJ } & \text { take.care.of } & \text { VRB } & 1 & \text { family } 1 \\ \text { a- } & \text { khe } & & & & \end{array}$

Following this approach, which comes out of a rejection of what Bruening (2017) calls the 'Lexicalist Hypothesis', we would first have to establish that Zulu relatives and relative clauses are in fact the same thing.

It should be noted that this approach to Zulu DPs assumes that individual syllables, sometimes consisting of a single vowel, are morphologically decomposable. This is entirely in line with approaches taken in a Distributed Morphology framework. So, for instance, Zulu (proximal) demonstratives, rather than consisting of 9 items that must be memorized by the native learner and associated with 14 possible classes, instead can be interpreted as a demonstrative $l$-, a functional $a$-, and a class agreement marker subject to the *NAS constraint. 14 separate lexical entries for the native speaker to memorize have been reduced with this approach to a single morpheme subject to the same structural and phonological constraints that occur elsewhere in the grammar. This approach also has the benefit of being firmly in line with other accepted analyses of similar phenomena (e.g., Spanish clitics in Halle \& Marantz 1994).

\begin{tabular}{llll} 
Class & Class marker & Demonstrative & Decomposition \\
\hline 1 & umu- & lo & $1-\mathrm{a}-\mathrm{u}\left(*^{\mathrm{m}}\right) \mathrm{u}$ \\
2 & aba- & laba & $1-\mathrm{a}-\mathrm{aba}$ \\
3 & umu- & lo & $1-\mathrm{a}-\mathrm{u}\left(*_{\mathrm{m}}\right) \mathrm{u}$ \\
4 & imi- & le & $1-\mathrm{a}-\mathrm{i}\left(*_{\mathrm{m}}\right) \mathrm{i}$ \\
5 & i(li)- & leli & $1-\mathrm{a}-\mathrm{ili}$ \\
6 & ama- & la & $1-\mathrm{a}-\mathrm{a}(* \mathrm{~m}) \mathrm{a}$ \\
7 & isi- & lesi & $1-\mathrm{a}-\mathrm{isi}$ \\
8 & izi- & lezi & $1-\mathrm{a}-\mathrm{izi}$ \\
9 & i(N)- & le & $1-\mathrm{a}-\mathrm{i}(* \mathrm{~N})$ \\
10 & izi(N)- & lezi & $1-\mathrm{a}-\mathrm{izi}(* \mathrm{~N})$ \\
11 & ulu- & lolu & $1-\mathrm{a}-\mathrm{ulu}$ \\
12 & izi(N)- & lezi & $1-\mathrm{a}-\mathrm{izi}(* \mathrm{~N})$ \\
13 & ubu- & lobu & $1-\mathrm{a}-\mathrm{ubu}$ \\
14 & uku- & lokhu & $1-\mathrm{a}-\mathrm{uku}$ \\
\hline
\end{tabular}

Table 6: Class markers, demonstratives, and a proposed decomposition of demonstratives

4.3 EVIDENCE FOR CONSTRUCT STATE? Returning to the discussion of construct state above, the evidence in Zulu is somewhat murky. Unlike other languages where deverbal nouns and infinitives are morphologically distinct, infinitives, gerunds, and deverbal nouns in Zulu are all marked with the $u k u$ - class prefix. The standard example of construct state, given in example 1, is reproduced in example 30. While it is possible to craft a parallel utterance in Zulu, the word ukubhuqwa 'destruction' must have a (verbal) passive suffix to be fronted (example 31, note the functional /a/). 
a. harisat ha- oyev 'et ha- 'ir

destruction the enemy OM the city

'the enemy's destruction of the city'

a. $\quad$ ukubhuqwa kwedolobha (y)isitha

$\begin{array}{llllllll}\text { uku- } & \text { bhuq- wa } & \mathrm{ku}- & \mathbf{a}- & \mathrm{i}- & \text { dolobha } & \text { isi- } & \text { tha } \\ 14 & \text { destroypass } & 14 & \text { /a/- } & 5 & \text { city } & 7 & \text { enemy }\end{array}$

'the enemy's destruction of the city'

That said, there is a clear difference between the nominal destruction in example 31 and the behavior of the equivalent verbal phrases in example 32.

a. isitha sabhuqa idolobha

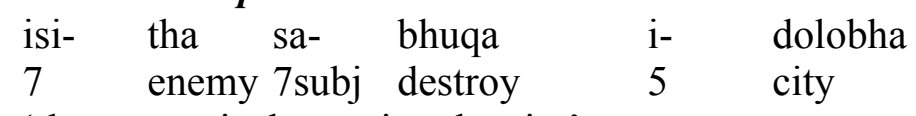

'the enemy is destroying the city'

b. idolobha labhuqwe (yisitha)

i- dolobha la- bhuq- w- e yi- tisha

5 city 5SUBJ destroyPASS PST cop.7 enemy

(active voice)

'the city was destroyed by the enemy'

More research is needed to tease apart difference precisely what is happening in expressions like those in example 31, especially with regards to the behavior infinitives, deverbal nouns, and gerunds. However, it seems clear that there is some evidence for construct state in Zulu, and that the noun phrase in 31, 'the enemy's destruction of the city' exhibits the functional /a/ we expect to find in complex nominals if the above analysis is correct.

5. Comparison against previous analyses. Other recent approaches are generally concerned with a subset of the above phenomena, and do not concern themselves with, say, the behavior of compound nouns, demonstratives, or possessives. They implicitly or explicitly assume that Zulu relatives are the same as relative clauses. This leads to either a situation in which the native learner must be assumed to learn an enormous number of individual morphemes for each grammatical category, missing a simpler generalization, or one in which a more complicated syntactic architecture must be posited. For instance, Pietraszko (To appear), examining Ndebele, ${ }^{7}$ notes the DP behavior of nouns modified by 'relatives', and argues both for an extra projection in DPs (LnkP, since the augment is assumed to be the head of D), and for DP shells, for which the proposed structure is that of example 33.

$$
\left[\mathrm{DP} \mathrm{D}^{\mathrm{o}}\left[\mathrm{CP} \mathrm{C}^{\mathrm{o}} \ldots\right]\right]
$$

I argue that this potentially adds unnecessary extra structure, predicated on Lexicalist assumptions, and at odds with the fact that many relatives (e.g., color terms) do not look or behave like CPs at all. Furthermore, part of the analysis in Pietraszko (To appear) is predicated on treating complementizer $u k u t h i$ 'that' as equivalent to $u k u t h i$ 'say', and therefore morphologically decomposable - specifically, assuming it has an augment. However, this assumption only potentially works for some complementizers (ukuthi 'that' 'to say' ukuba 'that,'

\footnotetext{
${ }^{7}$ A Nguni group language mutually intelligible with Zulu, which some scholars and native speakers argue to be a dialect of the same language (Mbeje, p.c.).
} 
'to be') and does not work for others (funa 'lest'). Moreover, verbs like 'say' very frequently grammaticalize as complementizers (Gouffé 1970, Kaisse \& Shaw 1985, Ebert 1991, Botne 1998, Deutscher 2000, Klamer 2000, Güldeman 2002).

The present approach is also at odds with much of the previous literature in terms of the treatment of noun augments. I tentatively propose that perhaps the reason noun augments have been analyzed as determiners in previous literature is not because they are actually determiners, but because they are frequently linearly adjacent to determiner/a/, which triggers phonological changes in a many environments. Keeping with the above analysis, it would be possible to treat NPI nominal as having a null determiner that triggers the deletion of a linearly adjacent augment, for instance. More work is needed to determine the precise role of the augment within this proposed framework, however it is clearly possible to address the same data within this framework. Moreover, the NPI nominal analysis in Halpert (2012) cannot be adduced to explain why augments are deleted in other environments.

6. Conclusion. There are two core theoretical differences in the above that have dramatic repercussions for the analysis of Zulu data. The first core distinction is whether one chooses to group relatives with other DP phenomena, or with CPs: are they basically behaving like adjectives or clauses? The second is how much work one believes the phonology is doing rather than the syntax. A phonology heavy analysis like that above reduces the assumed load on the native learner, and reduces many seemingly separate phenomena to a single, cross-linguistically familiar phenomenon.

The above approach demonstrates that "linking" $-a$ is present in a wider range of phenomena than normally assumed, and argues that it behaves like a functional head in all complex nominal. That is, all DPs with multiple elements exhibit this linking /a/. While more work is needed, the evidence suggest that the analysis of Zulu DPs can be brought into line with (simpler) analyses of other languages, and that there is some evidence for the construct state in Zulu.

\section{References}

Adger, David. 2003. Core syntax: A minimalist approach. Oxford: Oxford University Press. Bardeas, Suzanne. 2008. A minimalist approach to the semitic construct state. York Papers in Linguistics 9. 1-22.

Baker, Mark C. Agreement, dislocation, and partial configurationality. 2003. In Andrew Carnie, Heidi Harley, \& MaryAnn Willie (eds.), Formal approaches to function in grammar. 107-135. Amsterdam: John Benjamins.

Baker, Mark C. 2008. The syntax of agreement and concord. Cambridge: Cambridge University Press.

Borer, Hagit. 1999. Deconstructing the construct. In Kyle Johnson \& Ian Roberts (eds.), Beyond principles and parameters: Essays in memory of Osvaldo Jaeggli. 43-89. Dordrecht: Springer.

Botne, Robert D. 1998. Evolution of future tenses from serial 'SAY' constructions in central eastern Bantu. Diachronica 15(2). 207-30.

Bruening, Benjamin, 2017. The lexicalist hypothesis: Both wrong and superfluous. Unpublished manuscript.

Chomsky, Noam. 1995. The minimalist program. Cambridge, MA: MIT Press.

De Dreu, Merijn. 2008. The internal structure of the Zulu DP. Leiden: University of Leiden MA thesis. 
Deutscher, Guy. 2000. Syntactic change in Akkadian: The evolution of sentential complementation. Oxford: Oxford University Press.

Diercks, Michael. 2012. Parameterizing case: Evidence from Bantu. Syntax 15(3). 253-286.

Ebert, Karen H., 1991. Vom Verbum dicendi zur Konjunktion. Ein Kapitel universaler Grammatikentwicklung. In: P. Rinderknecht \& W. Bisang (Hrsg.), Von Europa bis Ozeanien - von der Antonymie zum Relativsatz. Gedenkschrift für Meinrad Scheller. Zürich: Seminar für Allgemeine Sprachwissenschaft. 77-95.

Embick, Dave. 2015. The morpheme: A theoretical introduction. Belin: Walter de Gruyter. Gouffé, Claude. 1970. Sur les emplois grammaticalisés du verbe 'dire' en haoussa. Comptes rendus du Groupe Linguistique d'Etudes Chamito-Sémitiques 15. 77-90.

Güldemann, Tom. 2002. When "say" is not say: The functional universatility of the Bantu quotative marker $t i$ with special reference to Shona. In Tom Güldemann \& Manfred von Roncador (eds.), Reported discourse: A meeting ground for different linguistic domains (Typological studies in language, vol 52). 253-288. Amsterdam: John Benjamins.

Halle, Morris \&Alec Marantz. 1994. Some key features of Distributed Morphology. MIT Working Papers in Linguistics. 21. 88.

Halpert, Claire. 2012. Argument licensing and agreement in Zulu. Cambridge, MA: MIT dissertation.

Kaisse, Ellen, and Patricia Shaw. 1985. On the theory of Lexical Phonology. Phonology 2(1). $1-30$

Kiparsky, Paul. 1982. Word-formation and the lexicon. Mid-America Linguistics Conference.

Klamer, Marian. 2000. How report verbs become quote markers and complementisers. Lingua 110. 69-98.

Khumalo, James. 1992. The morphology of the direct relative in Zulu. In Derek F. Gowlett (ed.), African linguistic contributions. 210-226. Pretoria: Via Afrika.

Larson, Richard and Hiroko Yamakido. 2005. Ezafe and the deep position of nominal modifiers. Barcelona Workshop on Adjectives and Adverbs.

Mbeje, Audrey. 2005. Zulu learners' reference grammar. Madison, WI: NALRC Press.

Mohanan, Karuvannur Puthanveettil. 1986. The theory of Lexical Phonology. Dordrecht \& Boston: Kluwer Academic.

Nyembezi, Cyril. 1957. Learn Zulu. Pietermaritzburg: Shuter and Shooter.

Perez, Carolyn. 1986. Aspects of complementation in three Bantu languages. Reproduced by the Indiana University Linguistics Club.

Pietraszko, Asia. To appear. Obligatory CP nominalization in Ndebele. Syntax.

Ritter, Elizabeth. 1988. A head-movement approach to construct-state noun phrases. Linguistics 26(6). 909-930.

Sabel, Joachim and Jochem Zeller. 2006. Wh-question formation in Nguni. In Selected proceedings of the 35th annual conference on African linguistics. 271-283. Somerville: Cascadilla Proceedings Project.

Serzisko, Fritz. 1987. The verb 'to say' in Ik (Kuliak). Afrikanistische Arbeitspapiere 11. 67-92. 